\title{
Pharmacokinetics of Gentamicin and its Interaction with Paracetamol after i.v. Administration in Buffalo Calves (Bubalus bubalis)
}

\author{
Baxla S.L1, Kumar $\mathbf{M}^{2}$, Jayachandran $\mathbf{C}^{2}$, Roy B.K ${ }^{1 *}$ and Kumari $\mathbf{A}^{2}$ \\ ${ }^{1}$ Department of Pharmacology \&Toxicology, College of Veterinary Science \& A.H, B.A.U., Ranchi-834006, India \\ ${ }^{2}$ Department of Pharmacology \& Toxicology, Bihar Veterinary College, R.A.U., Patna-800014, India
}

\begin{abstract}
The disposition kinetics was conducted in five healthy female buffalo calves following single i.v dose $(5 \mathrm{mg} / \mathrm{kg})$ of gentamicin alone and with paracetamol $(40 \mathrm{mg} / \mathrm{kg}$,i.v. $)$. The study revealed that the plasma concentrations of gentamicin were significantly higher when it was given with paracetamol as compared to alone between 0.042 to $0.333 \mathrm{hrs}$ and at 24 hrs. Serum concentrations of gentamicin was detected for longer period ( $48 \mathrm{hrs})$ in urine in both groups of experimental animals. In case of urine drug attained its peak level at the same time interval $(1.5 \mathrm{hrs})$ in both groups with the concentration of $83.42 \pm 3.14 \mu \mathrm{g} / \mathrm{ml}$ after alone and $545.1 \pm 25.85 \mu \mathrm{g} / \mathrm{ml}$ with paracetamol administration. The extrapolated zero time plasma concentrations during distribution phase $(A)$ and theoretical zero time plasma concentrations $\left(C^{\circ} \mathrm{p}\right)$ were significantly $(p<0.01$ ) higher $34.48 \pm 2.35$ and $39.03 \pm 2.40 \mu \mathrm{g} / \mathrm{ml}$ respectively. Also significantly higher distribution rate constant $(\alpha)$ of $1.935 \pm 0.1119 \mathrm{~h}^{-1}$ and lower distribution half life $\left(t_{1 / 2} \alpha\right)$ of $0.36 \pm 0.02$ hrs were observed, when gentamicin was given with paracetamol. Elimination half life $\left(\mathrm{t}_{1 / 2} \beta\right)$ of $6.67 \pm 0.11 \mathrm{hrs}$ was not significantly higher when gentamicin was given with paracetamol. AUC $(62.16 \pm 2.82 \mathrm{mg} / \mathrm{L}$.hrs $)$ was significantly $(p<0.05)$ higher while MRT $(6.93 \pm 0.36 \mathrm{hrs})$ was not significantly higher when gentamicin was given with paracetamol. The values of $\mathrm{K}_{12}, \mathrm{~K}_{21}$ and Kel were calculated to be $1.088 \pm 0.111 \mathrm{~h}^{-1}, 0.323 \pm 0.028 \mathrm{~h}^{-1}$ and $0.628 \pm 0.024 \mathrm{~h}^{-1}$ respectively when gentamicin was given concurrently with paracetamol. T P $(5.04 \pm 0.16)$ was significantly $(p<0.01)$ higher, while $\mathrm{Vd}_{\mathrm{d}}(0.78 \pm 0.03 \mathrm{~L} / \mathrm{Kg})$ and CIB $(1.35 \pm 0.06 \mathrm{ml} / \mathrm{Kg} / \mathrm{min})$ were not significantly higher when gentamicin was given with paracetamol. The present investigation established that both gentamicin and paracetamol interacted with altered their kinetic behaviour. The combination with paracetamol may be benificial because paracetamol reduced the maintenance doses of gentamicin which may be much advantageous in the field of veterinary practice in the dose of $5 \mathrm{mg} / \mathrm{kg}$ daily by systemic route and 36 hourly when given with paracetamol in urinary tract infection.
\end{abstract}

Keywords: Pharmacokinetics; Gentamicin; Paracetamol; Interaction; Intravenous; Buffalo calves

Abbreviations: A: Zero time plasma drug concentration during distribution phase; B: Zero time plasma drug concentration during elimination phase; $\mathrm{C}^{\circ} \mathrm{p}$ : theoretical zero time plasma drug concentration; $\alpha$ : distribution rate constant; $t_{1 / 2} \alpha$ : distribution half life; $\beta$ : Elimination rate constant; $t_{1} \beta$ : elimination half life; AUC: Area under curve; AUMC: Area under first moment curve; MRT: Mean residence time; $\mathrm{K}_{12}$ : Rate constants for drug transfer from central to peripheral compartment; $K_{21}$ : Rate constants for drug transfer from peripheral to central compartment; Kel: Rate constants for elimination of drug from central compartment; Fc: Fraction of drug in central compartment; $\mathrm{T} \sim \mathrm{P}$ : Tissue to plasma concentration; $\mathrm{Vd}_{\mathrm{c}}$ : Volume of the central compartment; $\mathrm{Vd}_{\mathrm{ss}}$ : Apparent volume of distribution at steady state; $\mathrm{Vd}_{\mathrm{B}}$ : Extrapolated volume of distribution; $\mathrm{Vd}_{\text {area }}$ : Volume of distribution by area; $\mathrm{Cl}_{\mathrm{B}}$ : Total body clearance

\section{Introduction}

Gentamicin, a broad spectrum aminoglycoside is widely used in infectious diseases of animals. It is used to treat various infections caused by aerobic Gram negative bacteria such as E.coli, Salmonella, Klebsiella, Proteus, Haemophilus, Pasteurella, Compylobactor and Pseudomonas. It binds to 30s ribosomal subunit; however, it also appear to bind to several sites on the 50s ribosomal subunit. It is therapeutically used in cases of urinary tract infections, bacteremia, infected burns, osteomyelitis, pneumonia, peritonitis and otitis.

Paracetamol, a potent antipyretic agent, having analgesic and anti-inflammatory properties and is widely used in man and animals for treating febrile conditions. Paracetamol indirectly blocks Coxenzyme and that this blockade is ineffective in the presence of peroxides. Cox also produces thromboxanes, which aid in the blood clotting, aspirin reduces blood clotting, but paracetamol does not. Thus paracetamol is effective in the central nervous system and in endothelial cells. It does not affect function of platelets and clotting factors and is less gastrointestinal irritant. It is a suitable substitute for aspirin for its antipyretic or analgesic actions.

Although pharmacokinetic study of gentamicin have been conducted in many species of animals,it seems little work has been done on kinetic interaction of gentamicin with NSAIDs in buffalo calves, particularly on the interaction of gentamicin with paracetamol. Therefore, the present experiment aims on the pharmacokinetic studies of gentamicin and its interaction with paracetamol after i.v. administration in buffalo calves.

${ }^{*}$ Corresponding authors: Dr. B.K.Roy, Uni. Prof. \& Chairman, Department of Pharmacology \&Toxicology, College of Veterinary Science \& A.H, B.A.U., Ranchi-834006, India, Tel: +91-651-2450759(o); Fax: +91-651-2450759(o); E-mail: roybk2001@yahoo.co.in

Received May 20, 2010; Accepted June 28, 2010; Published June 28, 2010

Citation: Baxla SL, Kumar M, Jayachandran C, Roy BK, Kumari A (2010) Pharmacokinetics of Gentamicin and its Interaction with Paracetamol after i.v. Administration in Buffalo Calves (Bubalus bubalis). J Bioanal Biomed 2: 065-068. doi:10.4172/1948-593X.1000024

Copyright: @ 2010 Baxla SL, et al. This is an open-access article distributed under the terms of the Creative Commons Attribution License, which permits unrestricted use, distribution, and reproduction in any medium, provided the original author and source are credited. 


\section{Materials and Methods}

\section{Animals}

Five clinically healthy female buffalo calves of non-descript breed, of 12 to 18 months age, weighing between 102 to180 $\mathrm{kg}$ were used in this experiment. The calves were procured by cattle breeding farm of Bihar Veterinary College Patna. They were maintained exclusively on grazing and also supplementary concentrate feeding was made for them with the provision of night shelter. Water was given ad libitum throughout the period of investigation. The protocol of the experiment was approved by Institutional Animal Ethics Committee.

\section{Drugs used}

Progenta ${ }^{\circledR}$, an injectable commercial preparation containing gentamicin in concentration of $40 \mathrm{mg} / \mathrm{ml}$ marketed by Vetsfarma (@5mg/kg b. wt) and Paracetol-vet ${ }^{\circledR}$-an injectable commercial preparation containing paracetamol in concentration of $150 \mathrm{mg} / \mathrm{ml}$ marketed by Sarabhai Zydus (@40mg/kg b.wt) were administered separately in each of five buffalo calves by i.v.route.An interval of 15 days was allowed to elapse before administration of next dose of the drug. After conducting kinetic study of gentamicin and paracetamol by i.v. route separately, both the drugs were administered together at above dose rate in each animal by i.v. route to identify the interaction if any.

\section{Collection of samples}

The samples of various biological fluids (plasma \& urine) were collected at 0.042, 0.083, 0.167, 0.25, 0.333, 0.50, $0.75 \mathrm{~min}$ and 1 , $1.5,2,3,4,5,6,8,10,12$ and 24 hrs. The samples of urine were collected further upto 48 hrs (30, 36 and $48 \mathrm{hrs})$.

\section{Blood}

Blood samples were collected in sterilized centrifuge tubes containing appropriate amount of sodium oxalate by vene-puncture with disposable $18 \mathrm{G}$ needle at above noted time intervals after drug administration. The blood samples were centrifuged at $3000 \mathrm{rpm}$ for $10 \mathrm{~min}$ for the separation of plasma and kept under refrigeration until assay was carried out.

\section{Urine}

Urine samples were collected in a sterile test tubes for analysis by introducing a sterile Foley`s balloon catheter (No. 12) lubricated with glycerine through urethra into urinary bladder of the experimental buffalo calves with the aid of a flexible metal probe. The balloon of the catheter was inflated by injecting $25-30 \mathrm{ml}$ of water through a syringe to keep the catheter in position. The opening of the catheter was blocked with a pressure clip to check dripping of urine.

\section{Analysis of gentamicin}

Estimation of gentamicin was carried out by microbiological assay technique (cylinder plate diffusion method) using Bacillus subtilis (ATCC 6633) as the test organism (Grove and Randell, 1955; Orsini et al., 1985). The culture of Bacillus subtilis was obtained from National Collection of Industrial Microorganism (NCIM), Division of Biochemical Sciences, National Chemical Laboratory, Pune- 8. The organism was grown on the slant of culture tube containing nutrient agar slants at $37^{\circ} \mathrm{C}$ for overnight. The organism was transferred weekly to fresh media to maintain its normal activity. Gentamicin was diluted in sterile glass distilled water to have different strengths viz.,
$80,40,20,10,5,2,1$ and $0.5 \mu \mathrm{g} / \mathrm{ml}$. From each of these solutions, $0.1 \mathrm{ml}$ was taken with the aid of micropipette and added to sterile vials containing $0.9 \mathrm{ml}$ of plasma or urine collected prior to drug administration. This yielded drug standards of $8,4,2,1,0.5,0.2$, 0.1 and $0.05 \mu \mathrm{g} / \mathrm{ml}$ in the respective biological fluids. These standard samples were stored in refrigerator and used simultaneously with test samples in assay plates for obtaining standard curve. 50 microlitres of each standard solution of various strength as well as test samples of the drug were poured in separate porcelin cylinder in the assay plate. The mean diameters of the bacterial zones of inhibition produced by the standard as well as test samples of the drug were measured. The standard curve was plotted from the measure of zone of inhibition against each concentration of the drug on a semi log scale. With the help of this standard curve and measured zone of inhibition $f$ different test sample, concentrations of drug in test samples were estimated.

\section{Analysis of paracetamol}

Paracetamol was estimated by spectrophotometric method (Archer and Richardson, 1980; Omer and Mohammod, 1984). Paracetamol was diluted in glass distilled water to different strength viz. 1000, 500, 250, 100, 50 and $20 \mu \mathrm{l} / \mathrm{ml}$. From each standard solution, $0.1 \mathrm{ml}$ was added to a sterile vials containing $0.9 \mathrm{ml}$ of plasma or urine collected prior to drug administration. These standards were simultaneously used along with test samples for the determination of drug concentrations in biological fluids.

\section{Pharmacokinetic analysis}

The pharmacokinetic parameters of gentamicin and paracetamol were calculated after its single i.v. administration from semi log plot of plasma drug concentration versus time curve. The experimental data was analyzed by using two compartment open model (Gibaldi and Perrier, 1975; Baggot, 1974; Notari, 1987). For a two compartment model, the concentration of the drug in plasma at any time is obtained from the formula.

$$
\mathrm{Cp}=\mathrm{Ac}^{-\alpha \mathrm{t}}+\mathrm{Be}^{-\beta \mathrm{t}}
$$

Where, $\mathrm{Cp}$ is the drug concentration in plasma at time' $t$ '. A, the zero time concentration of the drug in plasma and $\alpha$, the regression coefficient (distribution rate constant) for distribution phase were calculated by the method of residual yield. $B$, the zero time concentration of the drug in plasma and $\beta$, the regression coefficient (elimination rate constant) for elimination phase were calculated by the method of least squares.

\section{Calculation of dosage regimen}

Dosage regimen was calculated for antimicrobial agent to maintain minimum inhibitory concentration (MIC) in plasma at desired dosage intervals. Leroy et al. (1978) reported the therapeutic plasma levels (MICs) of gentamicin to be $1-4 \mu \mathrm{g} / \mathrm{ml}$. Hence, in the present study, dosage regimen of gentamicin were calculated at 1,2 and $4 \mu \mathrm{g} / \mathrm{ml}$ levels for the dosage intervals $(\gamma) 8$ and $12 \mathrm{hrs}$ using the formulas (Saini and Shrivastva, (1997).

$$
\begin{aligned}
& D^{*}=C_{p}^{\infty} \text { (min). } V d_{\text {area }}\left(e^{\beta \gamma}\right) \\
& D_{o}=C_{p}^{\infty}(\min ) \cdot V d_{\text {area }}\left(e^{\beta \gamma}-1\right)
\end{aligned}
$$

Where $\mathrm{D}^{*}=$ Loading or priming dose $(\mathrm{mg} / \mathrm{kg}), \mathrm{D}_{\mathrm{o}}=$ Maintenance dose $(\mathrm{mg} / \mathrm{kg}), \mathrm{C}_{\mathrm{p}}^{\infty}(\mathrm{min})=$ Desired minimum plasma concentration ( $\mu \mathrm{g} / \mathrm{ml}), \gamma=$ Dosage interval (hrs), $\beta$ and $\mathrm{Vd}_{\text {area }}$ were obtained from kinetic study. 


\section{Results}

Plasma concentrations of gentamicin were found to be significantly higher when it was given with paracetamol as compared to its alone administration from 0.042 to $0.333 \mathrm{hrs}$ and $24 \mathrm{hrs}$. (Figure 1). The therapeutic concentration $(\geq 2 \mu \mathrm{g} / \mathrm{ml})$ was maintained upto $6 \mathrm{hrs}$ in both the groups. Serum concentrations of gentamicin were detected upto 24 hrs in both the groups of buffalo calves. Concentrations of the gentamicin in urine were significantly higher from 0.083 to 24 hrs when gentamicin was given with paracetamol (Figure 2). The drug attained its peak level in urine at the same time interval of $1.5 \mathrm{hrs}$ in both the groups with a concentration of $83.42 \pm 3.17 \mu \mathrm{g} / \mathrm{ml}$ when gentamicin was given alone and $545.1 \pm 25.85 \mu \mathrm{g} / \mathrm{ml}$ with paracetamol. The mean therapeutic concentration in urine $(\geq 2 \mu \mathrm{g} / \mathrm{ml})$ was maintained up to $24 \mathrm{hrs}$ when gentamicin was given alone and 36hrs when given with paracetamol. The values of $A$, and $C^{\circ} \mathrm{p}$ were noted to be significantly higher $(p<0.01)$ in case of combined administration as compared to alone administration of gentamicin. Area under curve (AUC), area under first moment curve (AUMC) and micro rate constant from central to peripheral compartment $\left(K_{12}\right)$ were significantly higher $(\mathrm{p}<0.01)$ when gentamicin was given with paracetamol as compared to its alone administration. Rate constant of drug elimination from central compartment (Kel), and approximate tissue to plasma concentration ratio $(\mathrm{T} \sim \mathrm{P})$ were noted to be $0.628 \pm 0.024$ and $5.04 \pm 0.16$ for gentamicin when it was given with paracetamol. These values were significantly higher $(\mathrm{p}<0.01)$ as compared to alone administration of gentamicin. The value of distribution half-life $\left(t_{1 / 2} \alpha\right)$ was significantly $(\mathrm{p}<0.05)$ lower $(0.36 \pm 0.02 \mathrm{hrs})$ in combined administration of gentamicin as compared to its alonee administration $(0.69 \pm 0.08 \mathrm{hrs})$. The extrapolated zero time concentration during elimination phase (B),elimination rate constant $(\beta)$, elimination half life $\left(t_{112} \beta\right)$, mean residence time (MRT), rate constant of transfer of drug from peripheral to central compartment $\left(\mathrm{K}_{21}\right)$ and Vdarea did not differ significantly between both the groups (Table 1 ).

The calculated loading doses ( $\left.D^{*} s\right)$ for treating mild, moderate and severe systemic infections $\left(\mathrm{C}_{\mathrm{p}}^{\infty} \mathrm{min}=1,2\right.$ and $4 \mu \mathrm{g} / \mathrm{ml}$ respectively $)$ when gentamicin was given alone and with paracetamol, did not differ significantly while maintenance doses $\left(D_{0} s\right)$ were noted to be significantly lower $(p<0.05)$ for the dosage interval $(\gamma)$ of both 8 and 12 hrs when gentamicin was given along with paracetamol as compared to its alone administration. For treating moderate $\left(\mathrm{C}_{\mathrm{p}}^{\infty} \mathrm{min}\right.$ $=2 \mu \mathrm{g} / \mathrm{ml})$ and severe $\left(\mathrm{C}_{\mathrm{p}}^{\infty} \mathrm{min}=4 \mu \mathrm{g} / \mathrm{ml}\right)$ infections at $\gamma$ of $8 \mathrm{hrs} \mathrm{D*s}$ of 4.9 and $9.9, D_{0}$ s of 3.3 and $6.7 \mathrm{mg} / \mathrm{kg}$ were needed when gentamicin

Comparative Semilogerithmic plasma concentrations of Gentamicin alone and with paracetamol

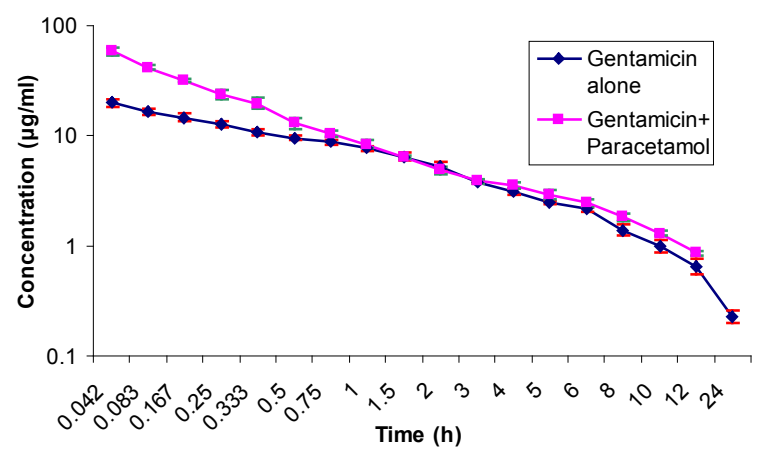

Figure 1:

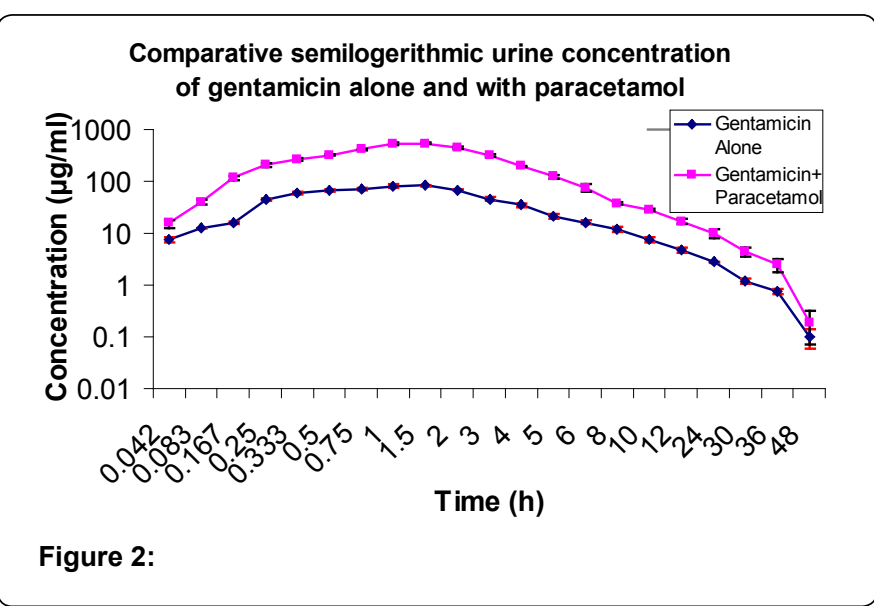

\begin{tabular}{|c|c|c|}
\hline Kinetic parameters (unit) & Gentamicin alone & Gentamicin + paracetamol \\
\hline $\mathrm{A}(\mu \mathrm{g} / \mathrm{ml})$ & $11.08 \pm 0.86$ & $34.48 \pm 2.35^{* *}$ \\
\hline $\mathrm{B}(\mu \mathrm{g} / \mathrm{ml})$ & $4.81 \pm 0.31$ & $4.41 \pm 0.21^{\mathrm{NS}}$ \\
\hline $\mathrm{C}^{\circ} \mathrm{p}(\mu \mathrm{g} / \mathrm{ml})$ & $15.89 \pm 0.85$ & $39.03 \pm 2.40^{* *}$ \\
\hline$A\left(h^{-1}\right)$ & $1.058 \pm 0.10$ & $1.935 \pm 0.119$ * \\
\hline$t_{1 / 2} \alpha(h r s)$ & $0.69 \pm 0.08$ & $0.36 \pm 0.02{ }^{*}$ \\
\hline$B\left(h^{-1}\right)$ & $0.139 \pm 0.008$ & $0.104 \pm 0.01^{\mathrm{NS}}$ \\
\hline $\mathrm{t}_{1 / 2} \beta$ (hrs) & $5.05 \pm 0.30$ & $6.67 \pm 0.11^{\mathrm{NS}}$ \\
\hline AUC (mg/L.hrs) & $45.90 \pm 3.10$ & $62.16 \pm 2.82$ * \\
\hline AUMC $\left(\mathrm{mg} / \mathrm{L} . \mathrm{h}^{2}\right)$ & $268.2 \pm 27.86$ & $433.1 \pm 28.63^{*}$ \\
\hline MRT (hrs) & $5.79 \pm 0.34$ & $6.97 \pm 0.36^{\mathrm{NS}}$ \\
\hline $\mathrm{K}_{12}\left(\mathrm{~h}^{-1}\right)$ & $0.425 \pm 0.054$ & $1.088 \pm 0.111^{*}$ \\
\hline $\mathrm{K}_{21}\left(\mathrm{~h}^{-1}\right)$ & $0.421 \pm 0.42$ & $0.323 \pm 0.028^{\mathrm{NS}}$ \\
\hline $\operatorname{Kel}\left(h^{-1}\right)$ & $0.351 \pm 0.023$ & $0.628 \pm 0.024^{\star *}$ \\
\hline $\mathrm{Fc}$ & $0.40 \pm 0.02$ & $0.17 \pm 0.01^{* *}$ \\
\hline $\mathrm{T} \sim \mathrm{P}$ & $1.54 \pm 0.16$ & $5.04 \pm 0.16^{* *}$ \\
\hline $\mathrm{Vd}_{\mathrm{C}}(\mathrm{L} / \mathrm{kg})$ & $0.32 \pm 0.02$ & $0.13 \pm 0.01^{* *}$ \\
\hline $\mathrm{Vd}_{\mathrm{B}}(\mathrm{L} / \mathrm{kg})$ & $1.05 \pm 0.06$ & $1.11 \pm 0.06$ * \\
\hline $\mathrm{Vd}_{\text {area }}(\mathrm{L} / \mathrm{kg})$ & $0.80 \pm 0.04$ & $0.78 \pm 0.03^{\mathrm{NS}}$ \\
\hline $\mathrm{Vd}_{\mathrm{SS}}(\mathrm{L} / \mathrm{kg})$ & $0.64 \pm 0.04$ & $0.56 \pm 0.04^{\mathrm{NS}}$ \\
\hline $\mathrm{Cl}_{\mathrm{B}}(\mathrm{ml} / \mathrm{kg} / \mathrm{min})$ & $1.86 \pm 0.16$ & $1.35 \pm 0.06^{\mathrm{NS}}$ \\
\hline SNon significant & $p<0.05$ & $* p<0.01$ \\
\hline
\end{tabular}

Table 1: Mean kinetic parameters of gentamicin alone $(5 \mathrm{mg} / \mathrm{kg})$ and with paracetamol $(40 \mathrm{mg} / \mathrm{kg})$ after i.v.administration in buffalo calves.

was given alone while lower $D^{*}$ s of $3.6 \& 7.1$ and $D_{0} s$ of 2.0 and 4.0 $\mathrm{mg} / \mathrm{kg}$ is required when gentamicin is given with paracetamol. Hence, shorter $\gamma$ of 8 hrs can be recommended.

\section{Discussion}

Distribution in plasma and urinary excretion as well as different kinetic parameters of gentamicin when given alone and in combination with paracetamol following i.v.administration interacted with one another. Paracetamol influenced the kinetics of gentamicin.Serum concentrations of gentamicin were detected upto 24hrs when gentamicin was given alone and when given with paracetamol whereas gentamicin was detectable only upto 6hrs in febrile and afebrile conditions of goat @ $5 \mathrm{mg} \backslash \mathrm{kg}$ after i.v. administration (Ahmad et al., 1994).The plasma concentrations of gentamicin were found to be significantly higher initially $(0.042$ to $0.333 \mathrm{hrs}$ ) when it was given in combination with paracetamol as compared to its alone administration. In case of urine, concentration of gentamicin persisted for a longer period (36hrs) when it was given with paracetamol. The $t_{112} \alpha$ was significantly lower $(0.36 \pm 0.02$ hrs) when gentamicin was given with paracetamol as compared to its alone administration $(0.69 \pm 0.08)$. The above findings of this experiment clearly indicated that paracetamol influenced the rate of distribution of gentamicin and gentamicin was distributed at a faster 
Citation: Baxla SL, Kumar M, Jayachandran C, Roy BK, Kumari A (2010) Pharmacokinetics of Gentamicin and its Interaction with Paracetamol after i.v. Administration in Buffalo Calves (Bubalus bubalis). J Bioanal Biomed 2: 065-068. doi:10.4172/1948-593X.1000024

rate in tissues and body fluids when it was given with paracetamol. The $t_{112} \alpha$ in other species were found to be low , $t_{112} \alpha$ of $0.05 \pm 0.01$ in cow (Satish et al.,1989), 0.1 \pm 0.1 hrs in horse (Swan et al.,1995), $0.38 \pm 0.07$ hrs rabbit (Uppal et al.,1992) and $10.25 \pm 1.42 \mathrm{~min}$ in chicken (Garg et al.,1989) as compared to the higher $t_{1 / 2} \alpha$ of $0.69 \pm 0.08 \mathrm{~h}$ obtained in present study. This showed that gentamicin was distributed comparatively slowly in buffalo calves as compared to other species noted above. Significantly higher AUC and AUMC may be due to higher plasma drug concentrations of gentamicin obtained from 0.042 to $0.333 \mathrm{hrs}$ and $24 \mathrm{hrs}$ when gentamicin was given with paracetamol. Significantly higher value of $K_{12}$ indicated faster movement of drug from central to peripheral compartment whereas $\mathrm{K}_{21}$ did not differ significantly in buffalo calves when gentamicin was given alone and with paracetamol. Significantly lower Fc along with significantly higher values of $\mathrm{K}_{12}$ and $\mathrm{T} \sim \mathrm{P}$ showed that gentamicin was distrbuted to a greater amount in peripheral tissues and fluids when it was given with paracetamol. The values of $\beta$ and $t_{1 / 2} \beta$ did not differ significantly. This indicated that similar rate of elimination occurred in both the groups and paracetamol had no influence in the elimination of gentamicin. Due to this MRT when gentamicin was given alone and when given with paracetamol also did not differ significantly. Lower $\mathrm{Vd}_{\text {area }}$ were studied by other researchers in other species for gentamicin, $\mathrm{Vd}_{\text {area }} 0.37 \pm 0.13 \mathrm{~L} / \mathrm{kg}$ in cow (Satish et al.,1989), $0.26 \pm 0.4 \mathrm{~L} / \mathrm{Kg}$ in goats (Garg et al.,1995), $0.45 \pm 0.11 \mathrm{~L}$ $\mathrm{Kg}$ in rabbit (Uppal et al.,1992) and $0.32 \pm 0.05 \mathrm{~L} / \mathrm{Kg}$ in White Leghorn chicken (Garg et al.,1989) as compared to present values $(0.80 \pm$ 0.04 and $0.78 \pm 0.03 \mathrm{~L} / \mathrm{Kg}$ ) when gentamicin was given alone and with paracetmol respectively in buffalo calves.This may indicate that gentamicin may be distributed to be a greater amount in the body of buffalo calves as compared to the above noted species.

Since, paracetamol reduces the doses of gentamicin and thus expected to prevent severe toxicity in buffalo calves, the study recommends that gentamicin can be successfully used along with paracetamol simultaneously for treating various systemic infections associated with pyrexia. In the present study, the mean therapeutic concentration $(\geq 2 \mu \mathrm{g} / \mathrm{ml})$ in urine was maintained upto $24 \mathrm{hrs}$ and $36 \mathrm{hrs}$ when gentamicin was given alone $(5 \mathrm{mg} / \mathrm{kg}$ i.v.) and when given with paracetamol (40 mg/kg i.v.), respectively. Hence, the study also recommends that gentamicin can be given by systemic route at $5 \mathrm{mg} /$ $\mathrm{kg}$ i.v daily at every $36 \mathrm{hr}$ when given along with paracetamol for treating urinary tract infections.

\section{Acknowledgements}

Authors acknowledge Dean, B.V.C, Patna and Vice-Chancellor, R.A.U. for providing fund for conducting this experiment.

\section{References}

1. Ahmad AH, Bahga HS, Sharma LD (1994) Pharmacokinetics of gentamicin following single dose intravenous administration in normal and febrile goats. J Vet Pharmacol Ther 17: 369-373.

2. Archer C, Richardson RA (1980) Estimation of paracetamol by spectrophotometric method. Ann Clin Biochem 17: 45.

3. Baggot JD (1974) Principles of drug distribution. Aust Vet J 50: 111-119.

4. Garg SK, Garg BD (1989) Disposition kinetics of gentamicin after repeated parenteral administration in the domestic fowl (Gallus domesticus). Acta Vet Brno 39: 323-330.

5. Garg SK, Jain SK, Garg BD (1989) Kinetic disposition and biotransformation of gentamicin in Gallus domesticus. Acta Vet (Beogr) 39: 323-330.

6. Garg SK, Verma SP, Uppal RP (1995) Pharmacokinetics of gentamicin following single-dose parenteral administration to goats. Br Vet J 151: 453-458.

7. Gibaldi M, Perrier D (1975) Pharmacokinetics. Marcel Dekkar. New York 175187.

8. Grove DC, Randell WA (1955) Assay methods of Antibiotics. Medical Encylcopedia: New York.

9. Haddad NS (1986) Pharmacokinetics of gentamicin in lactating cows after single intravenous, intramuscular and repeated intrauterine and intramuscular administration. Dissertation Abstracts International B 46: 4152-4153.

10. Leroy A, Humbert G, Oksenhendler G, Fillastre JP (1978) Pharmacokinetics of Aminoglycosides in subjects with normal and impaired renal function. Antibiot Chemother 25: 163-180.

11. Notari RE (1987) Biopharmaceutics and clinical pharmacokinetics, 3rd edn Marcel Dekker Inc., New York.

12. Omer VE, Mohammad FK (1984) Effect of antidotal N-acetylcysteine on the pharmacokinetics of Acetaminophen in dogs. J Vet Pharmacol Ther 7: 277-281.

13. Orsini JA, Soma LR, Rourke JE, Park M (1985) Pharmacokinetics of amikacin in the horse following intravenous and intramuscular administration. $J$ Vet Pharmacol Ther 8: 194-201.

14. Saini SPS, Srivastava AK (1997) pharmacokinetics and dosage regimen of amikacin in febrile cow calves. Indian J Anim Sci 7: 471-473.

15. Satish K Garg, Srivastava AK, Garg BD (1989) Kinetic disposition and dosage of gentamicin in pregnant cows. Ind Vet J 66: 414-417.

16. Swan GE, Guthrie AJ, Mulders MSG, Killeen VM, Nurton JP, et al (1995) Kinetics of gentamicin were determined in camels after i.v. and i.m. administration. J S Afr Vet Assoc 66: 151-156.

17. Uppal RP, Garg S, Verma SP, Roy RK (1992) Plasma disposition and biodistribution studies on gentamicin in rabbits. Indian J Pharmacol 24: 166168.

18. Uppal RP, Verma SP, Garg SK (1992) Disposition kinetics and dosage regimen of gentamicin in rabbits following intramuscular administration. Indian $\mathrm{J}$ Pharmacol 24: 36-37. 